The CoBaTrICE Collaboration

Received: 13 August 2010

Accepted: 8 November 2010

Published online: 17 December 2010

(C) Copyright jointly held by Springer and ESICM 2010

Electronic supplementary material

The online version of this article (doi:10.1007/s00134-010-2096-x) contains supplementary material, which is available to authorized users.

\section{On behalf of The CoBaTrICE}

Collaboration:

J.F. Bion (®). J.D. Wilde

University Department of Anaesthesia

and Intensive Care Medicine, N5,

Queen Elizabeth Hospital, Edgbaston,

Birmingham B15 2TH, UK

email: J.F.Bion@bham.ac.uk

Tel.: +44-121-627-2060

A. Bullock

School of Social Sciences,

Cardiff University, Wales, UK

Details of individual contributions are presented in the Appendix.

The CoBaTrICE Collaboration (

ESICM, Avenue Joseph Loybran 40,

Brussels, Belgium

e-mail: UniSecICM@uhb.nhs.uk

\title{
International standards for programmes of training in intensive care medicine in Europe
}

Abstract Purpose: To develop internationally harmonised standards for programmes of training in intensive care medicine (ICM).

Methods: Standards were developed by using consensus techniques. A nine-member nominal group of European intensive care experts developed a preliminary set of standards. These were revised and refined through a modified Delphi process involving 28 European national coordinators representing national training organisations using a combination of moderated discussion meetings, email, and a Web-based tool for determining the level of agreement with each proposed standard, and whether the standard could be achieved in the respondent's country. Results: The nominal group developed an initial set of 52 possible standards which underwent four iterations to achieve maximal consensus. All national coordinators approved a final set of 29 standards in four domains: training centres, training programmes, selection of trainees, and trainers' profiles. Only three standards were considered immediately achievable by all countries, demonstrating a willingness to aspire to quality rather than merely setting a minimum level. Nine proposed standards which did not achieve full consensus were identified as potential candidates for future review. Conclusions: This preliminary set of clearly defined and agreed standards provides a transparent framework for assuring the quality of training programmes, and a foundation for international harmonisation and quality improvement of training in ICM.

Keywords Intensive care .

Critical care - Training .

Accreditation - Standards . Quality assurance $\cdot$ CoBaTrICE

\section{Introduction}

The aim of the Competency Based Training in Intensive Care Medicine collaboration (CoBaTrICE) endorsed by the national intensive care medicine (ICM) training organisations of 43 countries, including all those of the European region ("Appendix"), is to optimise the care of critically ill patients and their families through the development of common standards for high-quality postgraduate training and education [1-3]. We began this unique collaboration by creating an international "product specification' for an intensivist through consensus development of intensive care competencies [4]. These competencies have been adopted by Croatia, Cyprus, France, Israel, Netherlands, Norway, Portugal, and the UK; and are in the process of adoption by Denmark, the Czech Republic, Greece, and Ireland. The second phase, which we report here, has been to develop internationally 
acceptable European standards for the 'production process'-that is, the programmes of training in ICM.

We determined the need for formulating standards for programmes of training in ICM through a prior survey of national training organisations about the training environment for ICM in the 28 countries of the European region [5]. In this survey, standards for training were highlighted as a particular area for improvement, with only $18(64 \%)$ countries having a formal national system for assuring the quality of ICM training, the majority using standards based on volume metrics (numbers of beds or admissions) and not the quality of the training experience. Across the 28 countries, only 14 (50\%) assessed the trainees during routine clinical activities using structured assessment and formal documentation and only six countries $(21 \%)$ recognised the work of trainers formally in a work plan or contract. Only one respondent expressed satisfaction with all aspects of training structures and processes. The paucity and variability of national training programme standards in ICM are potentially problematic because while variation in healthcare processes may be a strength [6] when the quality of the end-product is not in doubt, process standards become more important when the outcome in question is difficult to measure or complex $[7,8]$ as in the case of 'an intensivist'. The absence of standards also makes it more difficult to develop baseline metrics for quality improvement of training, and impedes the European goal of professional mobility across international borders, consistent with the aims of the Bologna declaration [9] and the European Association for Quality Assurance in Higher Education [10].

This survey provided the rationale for developing internationally acceptable European training programme standards to support trainers, enhance the training experience, reduce undesirable variation, and increase and harmonise quality improvement efforts in ICM across Europe. We now report the development of these standards using consensus techniques.

\section{Methods}

We used a combination of a nominal (expert) group, and a modified Delphi process to develop and achieve consensus on quality standards for programmes of training in ICM, based on our prior experience with the development of the intensive care competencies [2]. The Delphi process has many forms [11] but the common component is iterative modification of the items under discussion until full consensus is achieved or no further changes are proposed $[12,13]$. The number of iterations is therefore usually variable and not predefined. In order to achieve a balance between efficient use of time and resources while permitting maximum opportunities for interchange of ideas across Europe we employed group meetings, email, Web-based polling, and telephone calls in several stages (Fig. 1).

The steering committee predefined consensus criteria and cut-points as follows. Standards achieving full consensus $[100 \%$ of responding national coordinators (NCs) agreed or strongly agreed] were removed from further iteration and entered the final set. Standards were rejected if fewer than $75 \%$ of responding NCs agreed with their inclusion. Standards which achieved less than $100 \%$ but at least $75 \%$ agreement went through to the next iteration, and if full consensus could not be achieved these standards were then removed and categorised as suitable for future review. The final set of standards required formal approval by all 28 NCs. Proceedings were conducted in English.

Stage 1 of the study was the development of an initial draft set of standards by the expert group which consisted of nine participants and a moderator: of the nine participants, eight were European CoBaTrICE NCs representing their national ICM training programmes and one was a full-time senior healthcare executive who had previously been a senior academic intensivist. All participants were therefore highly experienced physicians and educators, nominated by their national training boards or societies. The group was moderated by an academic non-physician medical educationalist ("Appendix"). Preparatory work included asking participants to review their own national programme standards for plenary presentation. They met together for a 2-day workshop in June 2008, focussing on two questions: which aspects of training should be included in a quality assurance process? And, what minimum standards would be acceptable in your country? The expert group produced the initial standard-statements and grouped these into broad domains. After the meeting, members worked in pairs to clarify terminology; this then underwent further editing by the executive member of the working group, followed by revision by all members.

In stage 2 this first draft was circulated to all NCs in September 2008 for written comment, followed by a half-day meeting of all NCs or deputies at which detailed verbal comment was recorded by the research nurse and assimilated into the second revision by the project leads. This was then prepared as a Web-based survey for stage 3 .

In stage 3 all $28 \mathrm{NCs}$ reviewed the second iteration over a 2-month period, and rated each proposed standard using a Web-based structured feedback form. Respondents were asked to identify whether they agreed or disagreed with each proposed standard, and then to state whether it was achievable or not at present in their countries. They were invited to include their trainees in this process. The extent of agreement with each proposed standard was measured by using a four-point scale-agree strongly, agree, disagree, or disagree strongly. A 'neutral' 
Fig. 1 Consensus development process and outcomes

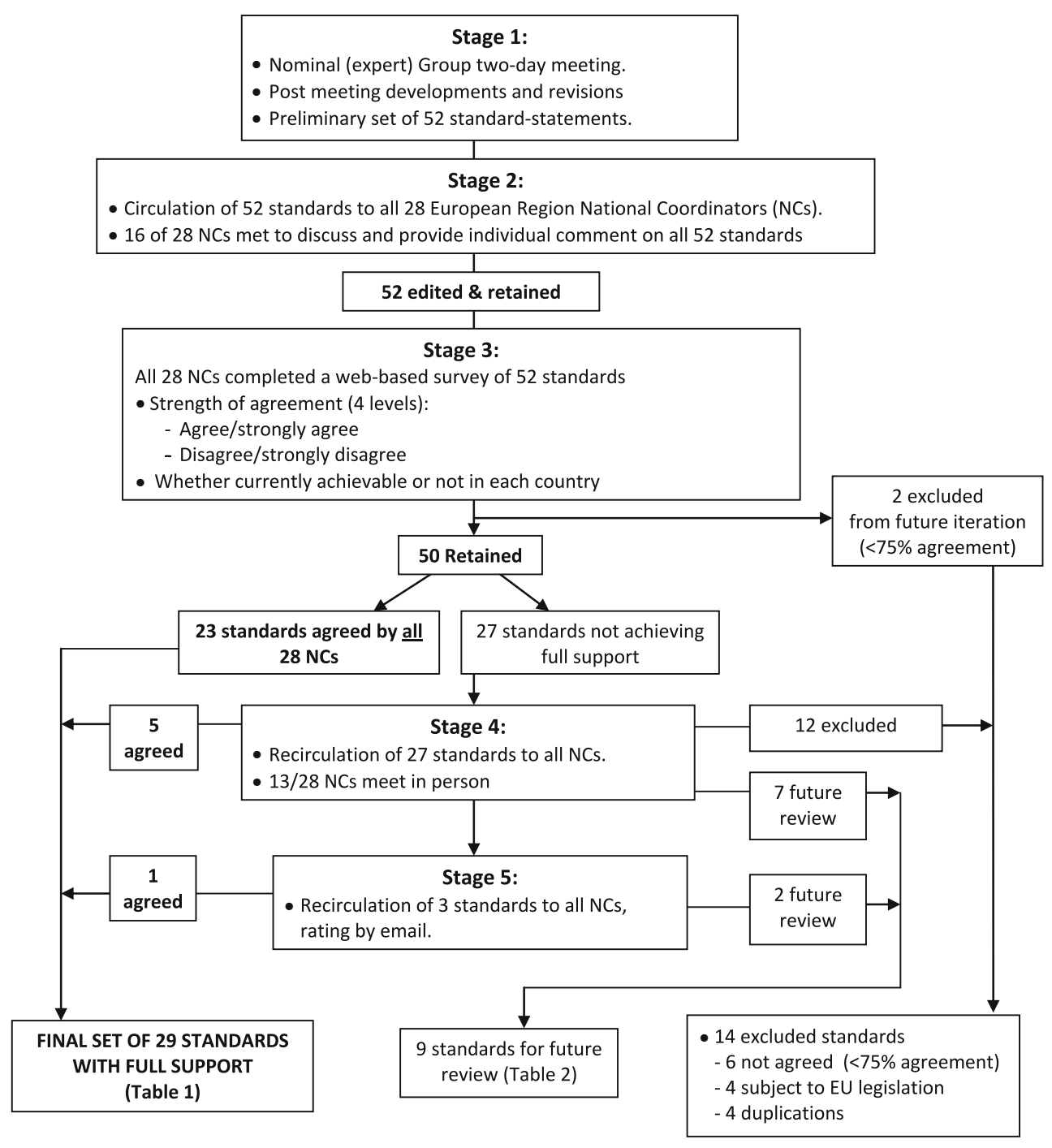

\section{Results}

Stage 1

response, respondents were able to add free-text commentary. Commentary from the NCs was used to clarify or modify standards where required. 'Achievability' was used as an indicator of likely difficulty with implementation, for example requiring investment of staff or resources for some countries.

In stage 4 , the remaining, revised or rephrased standards were redistributed to all $\mathrm{NCs}$ by email and discussed at the next project meeting in March 2009, allowing further modification. At this stage wording was clarified or amended and items removed if they were overlapping, lacking in clarity or covered by existing legislation. Proposed standards achieving full consensus were again removed from further iteration and placed in the final set.

In order for the remaining standards to be included in the final iteration (stage 5), 100\% consensus (agree or strongly agree) among NCs was required.
The nominal group developed 52 standards, which were grouped into four domains.

Stage 2

Responses to the first draft from all NCs were collated, and discussed at a project meeting. This permitted terminological clarification, and the 52 proposed standards (electronic supplementary material) then went through to stage 3 .

\section{Stage 3}

Of the 52 proposed standards, 23 were agreed by all 28 $\mathrm{NCs}$ and were therefore removed from further iteration and placed in the final set (Table 1). Of the remaining 29 
Table 1 The final set of standards

Agreement Achievability (\%)

$\begin{array}{ll}\text { Domain 1: training centres } \\ 1.01 & \text { Number of beds } \\ 1.02 & \text { Patients }\end{array}$

1.03 (a) and (b) Educational resources

$1.04 \quad$ Programme director

$1.05 \quad$ Accreditation

$1.06 \quad$ Audit activities

Domain 2: training programme

2.01 (a) and (b) Structures

2.02 (a), (b) and (c) Content

2.03 (a) and (b) Supervision

$2.04 \quad$ Feedback

2.05 Time for study

2.06 (a) and (b) Induction

2.07 (a), (b) and (c) Assessment

$2.08 \quad$ Research

Domain 3: selection of trainees

$3.01 \quad$ Background speciality

$3.02 \quad$ Selection processes

$3.03 \quad$ Language

Domain 4: trainers' profile

$\begin{array}{ll}4.01 & \text { Qualifications } \\ 4.02 & \text { Experience }\end{array}$

Experience

4.03 (a) and (b) Job description
Training ICUs must have 6 beds or more $\quad 100$

Training ICUs must provide verifiable evidence that $>25 \%$ of 100 their patients are ventilated $>24 \mathrm{~h}$, or $>40 \%$ of patient days are ventilator days

(a) There must be access to educational facilities and resources 100 (internet, library, study room) in training ICUs

(b) Careers advice must be available to all trainees

Training ICUs must be led by an ICU clinical director who has

been formally appointed for that unit

Each training ICU must be accredited by national training 100 authorities

Each training ICU must be able to provide evidence of regular 100 audit activities

(a) The training programme must have a defined syllabus, 100 modular structure and be competency based

(b) The training programme must provide continuous training 100 periods of at least 1 month

(a) Case mix available within the programme must be $\quad 100$ sufficiently diverse to allow acquisition of competencies

(b) The training programme must include non-technical 100 competencies: e.g. communication; collaboration; professional integrity

(c) The training programme must encourage lifelong learning 100

(a) The training programme must enable the trainee to acquire 100 increasing levels of responsibility

(b) Each trainee must have a named training supervisor $\quad 100$

Trainees must have a means of feeding back, in confidence, 100 their views of the training programme

Trainees must have protected time to attend relevant training 100 courses or educational meetings

(a) At the start of every training placement, trainees must meet $100 \quad 89$ with their training supervisor to set educational aims and objectives (personal learning plan or educational contract)

(b) At the start of every training placement, trainees must attend a departmental induction (introduction to team, instruction in unit and hospital policies and procedures)

(a) The training programme must have clear assessment processes (focussed on the workplace) which provide structured feedback

(b) The training programme must have mechanisms in place for supporting trainees in difficulty

(c) Trainees must maintain a learning portfolio

Trainees must be able to provide evidence of active participation in scientific research, audit or quality improvement

Trainees must be registered doctors and authorised to practise medicine in the country of the programme

There must be evidence that selection criteria and processes $\quad 100$ are clear and non-discriminatory

Trainees must be fluent in the national language of the $\quad 100$ programme

The training supervisor must be a practising intensivist

Trainers must be able to provide evidence of their own continuing professional development

(a) The training supervisor's role must be recognised by the national organisation(s) responsible for training in ICM

(b) The training supervisor's role must be contractually recognised by the employing organisation
86

61

86

89

99

.

.

9

36 
Table 2 Standards for future review

\begin{tabular}{|c|c|c|c|c|}
\hline Description & Standard-statement & Reason for review & $\begin{array}{l}\text { Agreement } \\
(\%)\end{array}$ & $\begin{array}{l}\text { Achievability } \\
(\%)\end{array}$ \\
\hline Nurses & $\begin{array}{l}\text { At least } 50 \% \text { of nurses in training ICUs } \\
\text { must have worked in IC for }>2 \text { years } \\
\text { or be trained and certified in IC } \\
\text { nursing }\end{array}$ & $\begin{array}{l}\text { Nurses were viewed as important to } \\
\text { physician training in ICM, but a suitable } \\
\text { internationally applicable metric could } \\
\text { not be agreed }\end{array}$ & 93 & 57 \\
\hline Educational resources & $\begin{array}{l}\text { There must be access to simulation } \\
\text { facilities (more than just CPR } \\
\text { mannequins) in the training ICU }\end{array}$ & $\begin{array}{l}\text { All supported the concept, but concerns } \\
\text { were expressed about simulation } \\
\text { facilities being high cost and not widely } \\
\text { available in many countries. A shortage } \\
\text { of trainers was also noted }\end{array}$ & 96 & 64 \\
\hline $\begin{array}{l}\text { Trainer to trainee } \\
\text { ratios }\end{array}$ & $\begin{array}{l}\text { One trainer must not train more than } 3 \\
\text { trainees at a time }\end{array}$ & $\begin{array}{l}\text { Trainer to trainee ratio was considered } \\
\text { important, but there was no evidence for } \\
\text { a specific ratio }\end{array}$ & 89 & 71 \\
\hline \multirow[t]{2}{*}{$\begin{array}{l}\text { Panel member training } \\
\text { and analysis }\end{array}$} & $\begin{array}{l}\text { Those on selection panels must be } \\
\text { trained in selection principles and } \\
\text { processes }\end{array}$ & $\begin{array}{l}\text { This is currently not an essential } \\
\text { requirement in many countries but is } \\
\text { becoming mandatory in others. This will } \\
\text { need further exploration regarding its } \\
\text { future inclusion and how such training } \\
\text { should be met }\end{array}$ & 86 & 54 \\
\hline & $\begin{array}{l}\text { The relationship between selection } \\
\text { criteria and end-of-training } \\
\text { performance must be analysed }\end{array}$ & $\begin{array}{l}\text { This refers to training programme } \\
\text { evaluation. Research is required to } \\
\text { compare inputs and outputs from } \\
\text { training programmes }\end{array}$ & 93 & 50 \\
\hline Qualifications & $\begin{array}{l}\text { The trainer must complete a recognised } \\
\text { trainers' course }\end{array}$ & $\begin{array}{l}\text { Access to 'training the teachers' courses is } \\
\text { difficult for some }\end{array}$ & 93 & 3 \\
\hline Specialty background & $\begin{array}{l}\text { Trainers from multiple disciplines must } \\
\text { be represented in the ICM training } \\
\text { programme }\end{array}$ & $\begin{array}{l}\text { Comments from respondents included } \\
\text { uncertainty about the utility of this } \\
\text { metric }\end{array}$ & 93 & 79 \\
\hline $\begin{array}{l}\text { Number of ICU } \\
\text { admissions }\end{array}$ & $\begin{array}{l}\text { The ICM training programme must } \\
\text { provide access to } 300 \text { admissions per } \\
\text { year }\end{array}$ & $\begin{array}{l}\text { Original numeric ( }>500 \text { admissions }) \text { was } \\
\text { unachievable for } 9(32 \%) \text { countries. The } \\
\text { standard requires further work to } \\
\text { identify the minimum numeric for } \\
\text { adequate training exposure }\end{array}$ & 75 & $68(>500)$ \\
\hline $\begin{array}{l}\text { Review of training } \\
\text { programme and } \\
\text { accreditation }\end{array}$ & $\begin{array}{l}\text { Each training programme must be } \\
\text { accredited every } 7 \text { years }\end{array}$ & $\begin{array}{l}\text { There was disagreement on length of time } \\
\text { for the process. Initially, 'every } 5 \text { years' } \\
\text { was not achievable by } 11(39 \%) \text { on } 1 \text { st } \\
\text { iteration }\end{array}$ & 75 & $\begin{array}{l}61 \text { (every } \\
5 \text { years) }\end{array}$ \\
\hline
\end{tabular}

standards, 27 achieved sufficient agreement $(\geq 75 \%)$ to enter the next iteration, and two were excluded $(<75 \%$ agreement). The two proposed standards which were excluded from further consideration were "ICUs with less than six beds can contribute to a clearly defined programme" (low agreement, high achievability), and "national examinations must be used in trainee selection processes" (low agreement, low achievability).

\section{Stage 4}

The 27 standards retained for further iteration were recirculated to all NCs, of whom 13 met in person. At this stage, five standards achieved complete agreement and entered the final set (Table 1). Seven achieved at least $75 \%$ but less than $100 \%$ agreement, could not be modified to the participants' universal satisfaction, and were reserved as suitable for future review (Table 2). Twelve were excluded from further iteration: four achieved less than $75 \%$ agreement, four were covered by existing legislation (e.g. training programmes must comply with the European working time directive), and four were captured in other standards and therefore redundant. Three standards remained for the next and final iteration.

\section{Stage 5}

Three statements were recirculated to all NCs by email. One of these achieved $100 \%$ agreement. The other two achieved more than $75 \%$ agreement, but consensus was not possible, and they were reserved for future review. Both of these had a numeric component and although both were deemed important by the NCs, the minimum number or length of time could not be agreed upon. The first of these originally read: "The ICM training programme must provide access to $>500$ admissions per 
year" (89\% agreed; $68 \%$ achievable). The number was reduced to ">300 admissions per year" which improved achievability but reduced agreement because of concerns about inadequate exposure. The second reserved standard was amended from "Each training programme must be accredited by national authorities at least every 5 years" to "at least every 7 years", but this diminished agreement further. Concerns included the absence of national quality assurance systems, and a tension with the speed of scientific developments in ICM.

The agreed set of standards

The final set of 29 standards (Table 1) achieved 100\% consensus (by definition): all 28 NCs either strongly agreed or agreed on their inclusion. The $100 \%$ consensus was achieved after stage 3 for 23 of these standards. After a further two stages, a further six propositions achieved $100 \%$ consensus. Only one standard was agreed strongly by all: that "the trainer must be a practising intensivist".

The final set includes standards which may not be immediately achievable in some countries: for five of the standards, fewer than $75 \%$ of the NCs judged them to be achievable. The standard likely to present most challenges in the short term is $4.03 \mathrm{~b}$ concerned with the contractual recognition of the supervisor's role.

\section{Standards for further review}

Nine propositions not achieving $100 \%$ consensus were identified for further review and are shown in Table 2. Most of these achieved high levels of agreement in their final iteration but presented difficulties in determining metrics or setting values. The standard referring to nurses is an example: the group clearly felt that nurses were important to physician training in ICM, but were unable to identify a suitable internationally applicable metric. The two with numeric components were the number of admissions, and the period of accreditation, as described above. The remaining seven standards in Table 2 require further definition or exploration which could not be achieved within the project time frame.

\section{Discussion}

We have used consensus techniques to develop a preliminary set of international standards for programmes of training in ICM, approved by the representatives of the national training organisations of all 28 European region countries. This represents the first step in addressing perceived weaknesses in quality assurance of ICM training identified from the earlier European survey [5]. These standards are fully consistent with the Bologna declaration [9] and the recommendations of the European Association for Quality Assurance in Higher Education [10]. Used in conjunction with the clinical competencies, the standards will facilitate trainee and specialist professional mobility, and demonstrate to trainees, trainers, programme directors, government bodies, patients and the wider public that the programme as a whole-the 'production process'-is of an acceptable standard.

The consensus method: outcomes and interpretation

The CoBaTrICE approach of developing standards using consensus amongst front-line staff who are also senior educators and representatives of their national training organisations enhances the viability and validity of these standards. Ongoing work will be required to review the standards themselves and their implementation. Once this preliminary set of standards has become embedded in national training programmes, the first review should involve more formal input from trainees and lay representatives. Although we have not set out to define "excellence", commitment to quality by the NCs was evident by the expression of agreement with standards that were judged to be not (yet) achievable, and rejection of those where the level was too low. The final set (Table 1) thus includes examples of standards which will be aspirational for some countries, and may be used by NCs and others in their arguments for change and development as well as further research.

Two of the standards within the training centre domain relate specifically to size and are expressed in terms of volume measures (1.01 ' 6 beds or more' and 1.02 'percentage of ventilator days'). These generated considerable discussion about the lack of evidence for a relationship between volume metrics and adequacy of training. Volume measures could exclude small but otherwise excellent ICU training centres, thereby preventing trainees from gaining experience in the type of hospitals where they may take up permanent specialist appointments. Arguably, having a sufficiently diverse case mix to enable acquisition of competencies (2.02a) is a sufficient indicator of adequacy. With specific reference to ventilator days, future medical advances might reduce the need for invasive ventilation, and thereby make it more difficult to achieve a specific volume measure. Volume-outcome metrics in education are an area for future research, and for this reason these standards should be kept under regular review. We should emphasise here that our focus has been on standards for programmes of training, and not solely on single training centres. Countries with modular programmes of training based on more than one centre will be able to meet volume measures without difficulty. 
Missing or excluded components

The final set of standards does not include any which refer to examinations, competence acquisition, or duration of training. It would have been difficult to mandate a common standard for examinations given the diversity of approaches across Europe [1] and the acceptance of workplace-based assessment of competence as the most appropriate measure of educational outcomes. A common European 'quality indicator' examination in the form of the European Diploma of ICM is clearly desirable, but best achieved through evolution rather than imposition of standards. A similar argument applies to competence acquisition: the CoBaTrICE competencies are increasingly accepted as the international standard, and the method has now been adopted by the USA [14], so there was no need to include them as a separate standard. Instead, national coordinators chose to develop standards which provided the best environment for the acquisition of those competencies (see 2.02a). A standard for duration of training would be difficult to justify given a competence-based programme in which trainees may require differing periods of training.

Comparisons with other approaches and systems

There is considerable diversity in approaches to standards development and accreditation of medical education worldwide [15], resulting in calls for the development of global standards for undergraduate training and qualification $[16,17]$.

At specialist, graduate level, the current diverse approach to quality assurance of ICM training programmes in Europe is described in our recent survey [5]. In Australia it is the responsibility of the Australian Medical Council to accredit (specialist) training organisations [18] to undertake peer assessment. The USA and Canada have a dispersed and a centralised system, respectively [19]. Accreditation of graduate training programmes in the USA is the responsibility of a private notfor-profit organisation, the Accreditation Council for Graduate Medical Education (ACGME), which produces common standards for all training centres and specialityspecific standards for each training programme. The speciality-specific standards are monitored and reviewed by review committees with professional input requested by email. This means that critical care (a subspeciality of four primary specialities) has four different sets of programme standards [20-22]. Harmonisation may eventually occur, with the development of common competencies across some disciplines, using the CoBaTrICE approach [14]. Canada by contrast has a centralised universal standard linked to the CANMEDS competencies, and therefore more shared standards between specialities [23, 24].
Implications for quality improvement

Standards of education should be developed and audited to improve training and patient care $[25,26]$. The programme standards presented here are a necessary, but not a sufficient, foundation for improving education and training in ICM. They must be combined with a dynamic quality assurance process delivered locally and managed by national training organisations [27, 28]. Regulatory authorities must recognise that quality assurance processes place significant demands on trainers, programme directors and professional organisations [29]. We propose therefore that these consensus standards should be seen as the foundation for a professionally owned, scientifically rigorous [30] dynamic process of quality improvement with the specific aim of improving the educational environment and hence creating better doctors delivering more reliable care.

\section{Conclusion}

The absence of training programme standards may result in a poor learning environment in which trainees fail to aspire to excellence. This first set of European standards focussed on the 'production process', coupled with the CoBaTrICE competencies should encourage national training organisations, trainers and trainees to drive up standards of training and clinical practice in ICM not only in Europe, but worldwide, with benefits for patients and families. If one accepts that effective regulation of medical education is vital because "social welfare is inextricably linked to the quality of the nation's physicians" [31], and Donabedian's perspective [32] that healthcare performance is influenced strongly by context, then common standards for training programmes will contribute to better patient care by a wider effect on the clinical environment.

The development of standards should be accompanied by research evaluation. Examples include surveys such as those organised in the UK by the General Medical Council [33], or the educational outcomes project in the USA supported by the Accreditation Council for Graduate Medical Education [34]. The work we have presented here provides the foundation for a formal European research programme evaluating the impact of quality assurance processes on vocational training, and for developing evidence-based medical education as a key component in improving healthcare outcomes.

Acknowledgments D. d'Hoir, N. Le Devic (European Society of Intensive Care Medicine); N. Middleton, B. Lafferty, C. Edwards (University of Birmingham); K. Tulkis, J. Aulehle, L. Beech, V. Wiggins (ECOTEC); C. van der Vleuten (University of Maastricht). The project is partly funded by a grant from the European Union Leonardo Da Vinci program, with support from the University of Birmingham, European Society of Intensive Care Medicine, Cardiff 
University, University of Maastricht, University of Mater Misericordiae, CYber Imagination and the simulation group SAInT.

\section{Appendix: the CoBaTrICE collaboration}

Principal author(s) A. Bullock, J.D. Wilde, J.F. Bion, on behalf of the CoBaTrICE collaboration.

Steering committee partners

J. Bion (CoBaTrICE originator, grant holder and cochair); J. Wilde (research nurse); A. Bullock (University of Cardiff and project co-chair); T. Clutton-Brock (University of Birmingham); H. Flaatten, N. Mathy (European Society of Intensive Care Medicine); W. Van Mook, L. Schuwirth (University of Maastricht); B. Marsh, D. Phelan (University of Mater Misericordiae); B. Shippey, G. Nimmo (SAInT affiliation); S. Castel, Y. Hillion, J. Bonnet, D. Chaumont (Cyber Imagination SAS); H.U. Rothen (Bern); H. Reay.

National coordinators and deputies [members of QA working group are highlighted]

C. Krenn, P. Germann (Austria); P. Ferdinande, D. De Backer (Belgium); I. Smilov, N. Keremidchieva (Bulgaria); V. Gašparoviæ, R. Radonic (Croatia); T. Kyprianou, M. Kakas (Cyprus); V. Sramek, V. Cerný (Czech Republic); L. Poulson, M. Skjekstad Simonsen, E. Ronholm (Denmark); S. Sarapuu, J. Starkopf (Estonia); T. Ala-Kokko, J.Pikkupeura (Finland); F. Saulnier, J. Duranteau (France); M. Quintel, R. Roissant (Germany); A. Armaganidis, A. Mavrommatis (Greece); Z. Molnár, A. Bede (Hungary); B. Marsh, D. Phelan (Ireland); P. Singer, J. Cohen (Israel); A. Gullo, F. Rubulotta (Italy); S. Kazune, I. Shapiro (Latvia); A. Van Zanten, A. Girbes (Netherlands); H. Flaatten (Norway); A. Mikstacki, B. Tamowicz (Poland); J. Pimentel, A. Carneiro (Portugal); R. Zahorec, J. Firment (Slovakia); G. Voga, R. Pareznik
(Slovenia); G. Gonzales-Diaz (Spain); L. Blanch (CIBERes, Spain); J. Wernerman, S. Rubertsson (Sweden); H.U. Rothen, M. Maggiorini (Switzerland); N. Ünal, B. Ceyda Orbey, A. Topeli Iskit (Turkey); K. Gunning, A. Batchelor, M. Shankar Hari (UK).

National reporters (NCs outside the European region)

L. Camputaro, A. Gallesio, S. Giannasi (Argentina); J. Havill (Australia, New Zealand); E. Knobel, S. Eliezer (Brazil); R.Hodder, D. Leasa (Canada); E. Celis (Chile); B. Du, K. Wang (China); G. Bugedo (Colombia); O. Palma (Costa Rica); V. Mwafonga (East Africa); Y. Khater (Egypt); C. Gomersall, G. Joynt (Hong Kong); S. Iyer, N. Ramakrishnan (India); M. Iqbal (Indonesia); T.Maekawa, T. Imai (Japan); T. Li Ling (Malaysia); T. De Guia (Philippines); G.G. Terzi (South America); T. Buckman, V.Kvetan, N. Stonis (USA); Y. Yapobi (West Africa).

\section{CoBa Trainee Advisory Group}

G. Roth, U. Thaler (Austria); L. Desmet (Belgium); T. Filipov (Bulgaria); A. Vujaklija (Croatia); A. Vlkova (Czech Republic); B. Riis-Anderson (Denmark); S. Bendel (Finland); F.Ganster, M. Darmon, J. Dellamonica (France); U. Bartels, T. Ninke, D. Schaedler (Germany); P. Kostis, A. Heleni, N. Maghina (Greece); A. Mikor, T. Leiner (Hungary); I. Hayes (Ireland); S. Lev, I. Kagan (Israel); L. Ferla, C. Santonocito (Italy); A. Van Hove (Netherlands); T. Albrecht (Poland); S. Teixeira, R. Freitas (Portugal); C. Sabatier, R. Peredo Hernandez (Spain); C. Passath, K. Auinger, D. Tuchscherer (Switzerland); A. Shah, N. Lees, S. Vamadevan, V. Navapurkar (UK).

Executive member of the Quality Assurance Working Group

Graham Ramsay (West Hertfordshire Trust, UK).

\section{References}

1. Barrett H, Bion JF, On behalf of the CoBaTrICE collaboration (2005) An international survey of training in adult intensive care medicine. Intensive Care Med 31:553-561

2. The CoBaTrICE collaboration (2006) Development of core competencies for an international training programme in intensive care medicine. Intensive Care Med 32:1371-1383
3. The CoBaTrICE collaboration (2007) The views of patients and relatives of what makes a good intensivist: a European survey. Intensive Care Med 33:1913-1920

4. CoBaTrICE (2010) http://www. cobatrice.org. Accessed 11 Aug 2010
5. The CoBaTrICE collaboration (2009) The educational environment for training in intensive care medicine: structures, processes, outcomes and challenges in the European region. Intensive Care Med 35:1575-1583

6. Lilford RJ (2009) Should the NHS strive to eradicate all unexplained variation? No. BMJ 339:b4811. doi: 10.1136/bmj.b4809 
7. NHS Confederation (2004) Variation in healthcare: does it matter and can anything be done? http://www. nhsconfed.org/Publications/Documents/ Variation\%20in\%20healthcare.pdf

8. Richards S (2009) Should the NHS strive to eradicate all unexplained variation? Yes. BMJ 339:b4811. doi: 10.1136/bmj.b4811

9. The European Higher Education Area (1999) Bologna declaration of 19 June 1999. Joint declaration of the European Ministers of Education, http://www. bologna-bergen2005.no/Docs/00Main_doc/990719BOLOGNA_ DECLARATION.PDF

10. European Association for Quality Assurance in Higher Education (2005) Standards and guidelines for quality assurance in the European higher education area. European Association for Quality Assurance in Higher Education, Helsinki. http://www. enqa.eu/files/BergenReport210205.pdf

11. Thompson M (2009) Considering the implication of variations within Delphi research. Fam Pract 26:420-424

12. Dakley NC (1969) The Delphi method: an experimental study of group opinion. Rand, Santa Monica, pp 1-79

13. Jones J, Hunter D (1995) Consensus methods for medical and health services research. BMJ 311:376-380

14. Buckley JD, Addrizzo-Harris DJ, Clay AS et al (2009) Multisociety task force recommendations of competencies in pulmonary and critical care medicine. Am J Respir Crit Care Med 180:290-295. doi:10.1164/rccm. 200904-0521ST

15. van Zanten M, Boulet JR, Simon FA (2010) Flexner's global influence: medical education accreditation in countries that train physicians who pursue residency in the United States. Acad Med 85:324-332. doi: 10.1097/ACM.0b013e3181c87638

16. Karle H (2006) Global standards and accreditation in medical education: a view from the WFME. Acad Med 81:S43-S48
17. World Federation for Medical Education (2003) Postgraduate medical education-WFME global standards for quality improvement: University of Copenhagen, Denmark. http://www. wfme.org/. Accessed 11 Aug 2010

18. Australian Medical Council (2010) Assessing specialist medical education and training. http://www.amc.org.au/ index.php/ar/sme. Accessed 11 Aug 2010

19. Cassie JM, Armbruster JS, Bowmer MI, Leach DC (2002) Accreditation of postgraduate medical education in the United States and Canada: a comparison of two systems. Med Educ 33:493-498

20. Accreditation Council for Graduate Medical Education (2007) ACGME institutional requirements checklist. http://www.acgme.org/acWebsite/irc/ IRCheckList-07.pdf. Accessed 11 Aug 2010

21. Accreditation Council for Graduate Medical Education: ACGME number of accredited programs for the current academic year. http://www. acgme.org/adspublic/reports/ accredited_programs.asp. Accessed 11 Aug 2010

22. Accreditation Council for Graduate Medical Education. ACGME program requirements submitted for review and comment. http://www.acgme.org/ acWebsite/reviewComment/ rev_programReq_Index.asp. Accessed 11 Aug 2010

23. The Royal College of Physicians and Surgeons of Canada (2009) General standards of accreditation. http://rcpsc. medical.org/residency/accreditation/ genstandards_e.pdf. Accessed 11 Aug 2010

24. The CanMEDS Physician Competency Framework (2010) http://rcpsc. medical.org/canmeds/index.php. Accessed 11 Aug 2010

25. Flexner A (1910) Medical education in the United States and Canada: a report to the Carnegie Foundation for the Advancement of Teaching. Carnegie Foundation for the Advancement of Teaching, New York
26. Sanazaro PJ (1976) Medical audit, continuing medical education and quality assurance. West J Med 125:241-252

27. Jones ML, Hobson RS, Plasschaert AJM, Gundersen S, Dummer P, RogerLeroi V, Sidlauskas A, Hamlin J (2007) Quality assurance and benchmarking: an approach for European dental schools. Eur J Dental Educ 11:137-143

28. Poorterman JHG, van Weert CM, Eijkman MAJ (1998) Quality assurance in dentistry: the Dutch approach. Int J Qual Health Care 10:345-350

29. De Vos M, Graafmans W, Kooistra M, Meijboom B, Van der Voort P, Westert G (2009) Using quality indicators to improve hospital care: a review of the literature. Int J Qual Health Care 21:119-129

30. Walshe K (2009) Pseudoinnovation: the development and spread of healthcare quality improvement methodologies. Int J Qual Health Care 21:153-159

31. Beck AH (2004) The Flexner report and the standardization of American medical education. JAMA 291:2139-2140

32. Donabedian A (2002) An introduction to quality assurance in health care. Oxford University Press, New York

33. Postgraduate Medical Education \& Training Board (2009) National training surveys 2008-2009. Postgraduate Medical Education \& Training Board: London. http://www.gmc-uk.org/ National_Training_Surveys_2008_09_ 20090929.pdf_30512348.pdf. Accessed 11 Aug 2010

34. Accreditation Council for Graduate Medical Education (2010) The Outcomes Project. (http://www. acgme.org/outcome. Accessed 3 Aug 2010 